\title{
ENVELHECIMENTO, MEIO AMBIENTE E EDUCAÇÃO AMBIENTAL
}

\author{
Anacirema da Silva Porciuncula ${ }^{1}$ \\ Ivalina Porto²
}

resumo

Neste artigo, procura-se descrever as relações proximais e conceituais de educação ambiental e suas articulações com os idosos, particularmente os institucionalizados. Esta pesquisa teórica e empírica embasou-se no que foi observado e coletado acerca das relações socioafetivas de quatro idosos residentes no Asilo de Pobres do Rio Grande. O objetivo principal deste estudo é provocar reflexões e questionamentos a respeito do envelhecimento humano na atualidade, considerando a influência que o meio ambiente exerce na qualidade do envelhecer. A pesquisa foi de cunho qualitativo e teve como base a Inserção Ecológica referendada na teoria bioecológica de desenvolvimento humano de Urie Bronfenbrenner. Efetuou-se uma consistente revisão bibliográfica na busca de maiores conhecimentos sobre o tema, utilizando-se como instrumentos de coleta de

1 Pedagoga e Doutoranda em Educação Ambiental pela Universidade Federal do Rio Grande (FURG). E-mail: aninhaporciuncula@hotmail.com

2 Doutoranda em Psicologia pela Universidad Pontificia de Salamanca. Professora Associada - Universidade Federal do Rio Grande (FURG). E-mail: ivalina@terra.com.br 
dados entrevistas semiestruturadas e diário de campo. A metodologia utilizada baseia-se na História de Vida, que permitiu estabelecer uma relação mais próxima com a população pesquisada e assim responder aos objetivos propostos. Concluiu-se que as questões relativas ao envelhecimento devem ser problematizadas pela sociedade através de ações educativas e ambientais que permitam um melhor desenvolvimento aos idosos. Os resultados obtidos neste estudo sugerem a criação de espaços educativos dentro da instituição, buscando recuperar a visão integral do ser humano e maior qualidade nas suas interações sociais e afetivas. $\bigcirc$ tema desta pesquisa é considerado relevante cientificamente devido ao aumento da expectativa de vida e, consequentemente, dos impactos sociais causados pelo crescimento demográfico da população idosa.

palavras-chave

Envelhecimento. Idoso. Educação Ambiental.

\section{Introdução}

Diante do envelhecimento populacional e da acelerada transição demográfica, resultantes do aumento da expectativa de vida e redução das taxas de natalidade, justifica-se a importante discussão sobre a temática do envelhecimento, meio ambiente e o lugar que a educação ambiental ocupa neste território. Compreender como os fatores naturais e sociais exercem influências na qualidade de vida dos idosos, principalmente aqueles que residem em instituições, tornou-se questão fundamental para toda sociedade.

Justifica-se aqui o interesse de estudo com idosos institucionalizados, a partir do contato que tive como pós-graduanda junto ao Asilo de Pobres da Cidade do Rio Grande-RS nos anos de 2004 (Pós-Graduação em Educação Brasileira - FURG) e 2008 (Pós-Graduação em Psicopedagogia Clínica e Institucional - Portal Faculdades), onde se tornou um grande desafio pessoal e profissional compreender melhor a realidade desta população. Durante as visitações realizadas na instituição, percebi a grande apatia e a indiferença que a maioria dos idosos sentia pela vida, o que acabou me motivando a pesquisar sobre as relações sociais e afetivas dos mesmos.

O Asilo de Pobres foi fundado na cidade de Rio Grande no estado do Rio Grande do Sul, em 27 de dezembro de 1885, por Antônio da Costa Corrêa 
Leite, Carlos Guilherme Rheingantz e Arnaldo José Pereira, sob a denominação de "ASYLO DE MENDIGOS". Está situado na Rua 24 de maio, no 571, bairro centro. É uma instituição civil privada, de caráter beneficente, filantrópico, destinada a proteger a velhice e a invalidez desamparada.

O Asilo de Pobres tem por finalidade contribuir tanto quanto possível para evitar a mendicidade pública, abrigando e sustentando, na medida dos seus recursos, pessoas de ambos os sexos, reconhecidos como indigentes e desamparados que, por velhice ou incapacidade física, se encontram impossibilitados de trabalhar. Este trabalho é realizado através dos recursos legados e donativos destinados a abrigar aqueles que eventualmente se encontrem sem amparo.

No ano de 2010, foi confirmada a residência no asilo de quarenta e três asilados e vinte e um pensionistas. A faixa etária deles, segundo a administração, varia entre 60 a 95 anos. A instituição em estudo não é amparada pelo poder público. Os recursos financeiros mantedores das atividades existentes são provenientes de aluguéis de apartamentos mais sofisticados que uma pequena minoria consegue usufruir (pensionistas) e de doações.

A Síntese de Indicadores Sociais (SIS) 2012 mostra que o índice de envelhecimento no Brasil cresceu de 31,7 em 2001, para 51,8 em 2011 comprovando que o Brasil é um País que caminha rapidamente para o envelhecimento populacional. O índice de envelhecimento aponta que em dez anos, o número de idosos com 60 anos ou mais passou de 15,5 milhões (2001) para 23,5 milhões de pessoas (2011). A participação relativa deste grupo na estrutura etária populacional aumentou de $9,0 \%$ para $12,1 \%$, no período, enquanto a de idosos com 80 anos ou mais chegava a 1,7\% da população em 2011.

Para que seja possível a sociedade acompanhar qualitativamente a longevidade humana, se faz necessário, em todas as etapas da vida, incluir a temática 'velhice' no cotidiano familiar, escolar e em espaços que promovam o pensar sobre como envelhecer sem os estereótipos negativos que o envelhecimento e a sociedade produzem.

Ost et al. (2009, p. 189) escreve a respeito dos conflitos da velhice:

Especificadamente com relação à velhice, esta etapa da vida está marcada pela oitava e última idade do desenvolvimento psicossocial do ser humano: a integridade do ego ou o desespero. Nessa fase, os adultos mais velhos, passam pelo processo de avaliação, resumo e concordância de suas vidas, para aceitar a aproximação com a morte. Aqueles que, ao fazerem esta análise, não encontram grandes motivos para orgulho pessoal e contentamento, tenderão ao desespero. O tempo passou, a morte está chegando, e nada mais de duradouro poderá ser iniciado. Erikson (1998) argumenta que a pessoa não deve chegar a esta fase 
com o tormento de que "deveria ter feito" mais ou "poderia ter sido" melhor. A certeza de que viveu uma vida produtiva trará uma maior aceitação na hora da morte, que se mostra adjacente.

Na Política Nacional do Idoso, Lei n. ${ }^{\circ} 8.842 / 94$ no art. 3º, inciso II, afirma-se em um dos seus princípios que: "o processo de envelhecimento diz respeito à sociedade em geral, devendo ser objeto de conhecimento e informação para todos". Diante do acima exposto destaca-se a relevância deste estudo em apresentar um panorama do tema em foco, articulando conceitos sobre: envelhecimento, meio ambiente e educação ambiental, interligando esses conceitos aos resultados de um trabalho de pesquisa que teve por foco as relações sociais e afetivas de idosos moradores do Asilo de Pobres do Rio Grande.

Com base no exposto, a presente pesquisa teve o objetivo de provocar reflexões e questionamentos a respeito do envelhecimento humano na atualidade, considerando a influência que o meio ambiente exerce na qualidade do envelhecer. Em decorrência da progressiva longevidade humana, se faz necessário políticas públicas cada vez mais capacitadas para dar qualidade de vida a esse segmento etário.

\section{Referencial teórico}

Quando se procura aqui uma definição sobre o que é meio ambiente, concorda-se com Reigota (2009, p. 36), que assim o define:

Defino meio ambiente como: um lugar determinado e/ou percebido onde estão em relações dinâmicas e em constante interação os aspectos naturais e sociais. Essas relações acarretam processos de criação cultural e tecnológica e processos históricos e políticos de transformações da natureza e da sociedade.

A partir deste conceito, pensa-se em uma perspectiva educativa que direcione essas transformações sociais, culturais e tecnológicas em benefícios para a humanidade, minimizando seus impactos no ambiente natural, visando uma consciência global dos problemas ambientais e despertando sentimentos de conservação e de integração com o meio. Daí, a Educação Ambiental como uma educação envolvida na conservação dos recursos naturais e também na transformação de atitudes e valores humanos.

A educação ambiental tem por objetivos a promoção da qualidade de vida e a transformação social, estando ela comprometida em atender a conservação do meio ambiente e suas complexas relações, proporcio- 
nando a dialogicidade entre os indivíduos e instituições sem discriminações. Sendo este diálogo indiscutivelmente fator emergente também na velhice devido ao crescimento demográfico da população idosa na atualidade e seus impactos ambientais. Assim referem-se Camarano e Kanso (2010, p. 95) sobre o aumento da expectativa de vida da população idosa e o aspecto fisiológico do envelhecimento:

\begin{abstract}
Embora a expectativa de vida da população brasileira em idade avançada esteja aumentando e esteja acompanhada por uma melhoria nas condições de saúde, o número de idosos com perda de autonomia para as atividades do cotidiano tende a aumentar. Embora haja alguma evidência de uma redução na proporção de pessoas com dificuldades para as atividades da vida diária, isso pode não resultar em menos pessoas demandantes de cuidados. $\bigcirc$ envelhecimento da população expõe os indivíduos por um tempo maior a doenças crônico-degenerativas, o que resulta em um número crescente de indivíduos sem autonomia e independência. Em outras palavras, a tendência esperada é de um aumento na demanda por cuidados.
\end{abstract}

Neste sentido, Ferreira et al. (2012, p. 383) assim corrobora: “A população idosa faz-se crescente, e as instituições de longa permanência constituem-se, muitas vezes, na única opção para esses indivíduos e suas famílias $[\ldots]^{\prime \prime}$. Instiga-se com esta afirmativa a necessidade de se (re)pensar e (re)criar o ambiente sócio-físico dos asilos em espaços contínuos de aprendizagem e criatividade e não apenas em "espaços de sobrevivência" de idosos.

A pesquisa teve como base a Teoria Bioecológica do Desenvolvimento Humano (TBDH), de Urie Bronfenbrenner (2002) que traz uma nova perspectiva para a compreensão do desenvolvimento humano, problematizando as interações entre os sujeitos e os vários níveis de ambientes que são por eles frequentados.

O modelo reformulado da Teoria Ecológica do Desenvolvimento Humano (1979) para a Teoria Bioecológica do Desenvolvimento Humano (1995) integra: processo, pessoa, contexto e tempo (PPCT). A organização do ambiente ecológico se dá como um encaixe de estruturas concêntricas, observando as relações interpessoais em ambientes mais próximos como a família, aos mais amplos como o contexto social, econômico e político dos indivíduos.

O ambiente ecológico, lugar onde as pessoas interagem, ou seja, o que se encontra fora do organismo é estruturado em quatro níveis ambientais: microssistema, mesossistema, exossistema e macrossistema. Explicando brevemente os conceitos, assim seria:

- Microssistema: o complexo de inter-relações dentro do ambiente imediato, face a face. Ex.: a família. 
- Mesossistema: influências advindas das inter-relações entre os microssistemas. Ex.: a escola.

- Exossistema: um ou mais ambientes que não envolvem diretamente a pessoa em desenvolvimento, mas no qual ocorrem eventos que afetam de alguma forma o ambiente em que está inserida. Ex.: local de trabalho dos pais.

- Macrossistema: compõe os valores culturais, crenças, situações sociais e acontecimentos históricos que afetam os outros sistemas ecológicos. Ex.: ideologias.

Com o objetivo de contribuir para as descobertas teóricas e empíricas do desenvolvimento humano Bronfenbrenner (2002) afirmou que a pessoa em desenvolvimento não é uma tábula rasa sobre a qual o meio provoca seu impacto, mas como uma entidade em crescimento, dinâmica que acaba por reestruturar o próprio meio em que reside.

Diante disso, considera-se que os múltiplos fatores de interação de natureza biológica, social, psicológica interferem no desenvolvimento humano e em suas relações entre os ambientes frequentados. Perceber quais são os papéis desempenhados pelos idosos e principalmente os asilados e suas interações com o meio constitui-se em elemento necessário para a compreensão do seu microssistema.

Bronfenbrenner (2011, p. 45) acrescenta: "No modelo bioecológico, os elementos objetivos e subjetivos são apontados como dirigindo o percurso do desenvolvimento humano; nenhum deles, por si, é presumido como suficiente". Assim, compreende-se a relação com o ambiente como elementos objetivos durante todo o ciclo vital e os sentimentos e experiências pertencentes à esfera subjetiva. Este modelo teórico tem sido uma evolução para o estudo científico do desenvolvimento humano ao longo do tempo.

\section{Metodologia}

Para a realização desta pesquisa, foram selecionados inicialmente um grupo de dez idosos de ambos os sexos, com idade entre 60 a 80 anos escolhidos pela instituição pesquisada como pessoas em boas condições físicas e mentais para fornecer os subsídios para este estudo. Após, individualmente, foi apresentada a proposta de pesquisa e o convite para participação. Foram então selecionados 04 (quatro) idosos que se propuseram a narrar suas histórias de vida e a participar dos encontros semanais. Alguns idosos acabaram não aceitando o convite justificando a recusa pelo receio de que as recordações passadas pudessem comprometer sua saúde física e emocional. 
Apresento brevemente os quatro idosos selecionados com os respectivos pseudônimos ${ }^{3}$ destacando algumas características particulares:

- Dona Vera Maria: ingressou no Asilo de Pobres do Rio Grande em 2001, segundo dados da administração. A data de nascimento que consta no registro é 03/10/1921. Dona Vera Maria foi levada ao asilo por sua filha, com quem morou alguns anos antes de chegar à instituição. Diante dos problemas de saúde do genro e os maus tratos do neto esquizofrênico, o asilo foi a única opção que lhe restou de moradia. Dona Vera Maria, aposentada, divide o mesmo quarto com outros idosos;

- Dona Carolina ingressou no Asilo de Pobres do Rio Grande em 2004. A data de nascimento que consta no registro é 28/09/1922. Viúva e com o único filho já falecido, Dona Carolina foi sugestionada pelo irmão, também já falecido, a morar no asilo. Pensionista, tem o privilégio de desfrutar de um quarto somente para ela e de pagar uma acompanhante todas as noites;

- Dona Eugênia ingressou na referida instituição em 2009 e a data de nascimento que consta no registro é 18/01/1932. Depois que ficou viúva, ainda morou sozinha, com acompanhante à noite, durante dez anos. Depois que adoeceu, não conseguiu mais ficar em sua casa. Foi convidada pelas filhas para morarem juntas, mas Dona Eugênia não quis. Justificou que não queria dar trabalho para ninguém e decidiu ir para o asilo. Dona Eugênia, aposentada, divide o seu quarto com outros idosos;

- Dona Lúcia Helena ingressou na referida instituição em 2009 e a data de nascimento que consta no registro é 30/03/1932. Sendo pensionista, faz uso de um quarto individual com banheiro privativo. Dona Lúcia Helena disse que não quis ficar morando em sua casa com o seu filho, pois o mesmo bebe. Procurou pelo asilo para residir e afirmou gostar da comida e se dar bem no local.

A metodologia utilizada neste estudo foi a Pesquisa Qualitativa, por meio de História de Vida. Essa metodologia busca conhecer as experiências de vida dos sujeitos dando atenção às suas memórias, fazendo com que esses mesmos sujeitos "reapareçam" como indivíduos singulares e ao mesmo tempo plurais, pois se encontram inseridos num contexto social. Para Chizzotti (2008, p. 101):

História de Vida é um relato retrospectivo da experiência pessoal de um indivíduo, oral ou escrito, relativo a fatos e acontecimentos que foram significativos e constitutivos de sua experiência de vida. História de vida pode significar muitas coisas, dependendo dos objetivos ou dos pressupostos teóricos do pesquisador.

3 Para desidentificar as participantes os nomes foram trocados e foi informado apenas o ano de ingresso no Asilo. 
A história de vida de cada participante foi construída a partir de visitas semanais na instituição, utilizando os instrumentos a seguir citados, como materiais selecionados para a constituição das narrativas profundas, compartilhadas entre o pesquisador e os entrevistados. Os materiais submetidos à análise tiveram suas origens em entrevistas semiestruturadas, diário de campo, registro visual (fotografia) e outras fontes de informação disponíveis sobre os fatos, o contexto e a própria pessoa.

Nas entrevistas semiestruturadas não foi criado um roteiro fixo e sim, perguntas fechadas e abertas em blocos, divididas em fases da vida, como: $a$ infância, a juventude, a vida adulta e a velhice. Solicitei aos idosos que narrassem as lembranças que tinham de quando eram crianças até o momento em que se encontravam, questionando-os, sempre individualmente. Foi utilizado, como recurso para as entrevistas semiestruturadas, o uso de gravador de voz. As entrevistas foram transcritas na íntegra e encontram-se arquivadas com a pesquisadora.

O diário de campo foi adotado também como instrumento para coleta de dados nesta pesquisa, visando registrar fatos, sentimentos e percepções da pesquisadora que não fizeram parte do material formal de entrevistas, onde as informações escritas foram utilizadas posteriormente na análise dos dados. As fotografias tiradas pela pesquisadora, focando principalmente a fachada do asilo e algumas de suas dependências, sem a pretensão de divulgar a imagem dos idosos.

Outros materiais foram submetidos à análise. Citam-se conversas informais com funcionários, amigos e visitantes da instituição pesquisada, a fim de saber um pouco mais sobre cada idoso.

Dentre as diversas formas de análise da coleta de dados advindas da narrativa das histórias de vida foi escolhida a Análise Temática. A análise temática consiste em descobrir os núcleos de sentido que compõem a comunicação, objetivando explicitar as informações e significados pertinentes nela contidos. A análise dos dados coletados foi apresentada em quadros individuais e sintetizada sobre a história de vida de cada idoso.

O referencial para a construção dos quadros de análise partiu da teoria de Jovchelovitch e Bauer (2002, p. 107), onde através da análise temática se constrói gradualmente uma redução de texto qualitativo, como assim referem-se:

Recomenda-se um procedimento gradual de redução do texto qualitativo (veja, por exemplo, Mayring, 1983). As unidades do texto são progressivamente reduzidas em duas ou três rodadas de séries de paráfrases. Primeiro, passagens inteiras ou parágrafos, são parafraseados em sentenças sintéticas. Estas sentenças são posteriormente parafraseadas em alguma palavra-chave. Ambas as reduções operam com generalização e condensação de sentido. Na prática, o texto é colocado em três colunas; a primeira contém a transcrição, a segunda contém a primeira redução, e a terceira coluna contém apenas palavras-chaves. 
Sendo assim, Jovchelovitch e Bauer (2002, p. 107) corroboram ainda mais quando afirmam que "O produto final constitui uma interpretação das entrevistas, juntando estruturas de relevância dos informantes com as do entrevistador [...]". Os quadros para análise foram construídos conforme modelo abaixo:

Quadro 1 - Análise de entrevista narrativa - Pseudônimo: Vera Maria (19/06/2010)

\begin{tabular}{|c|c|c|}
\hline Transcrição & Paráfrases & Palavras-chave \\
\hline $\begin{array}{l}\text { Pesquisadora: "Dona VM, me conta como é } \\
\text { que foi a sua infância..." }\end{array}$ & & \\
\hline $\begin{array}{l}\text { VM: "Ótima... Mamãe tratava nós e papai } \\
\text { bem. Eram turco né. Nós falava com } 6 \\
\text { anos, nós já falava árabe. E nós assim... na } \\
\text { cozinha, nós se rolava, dançava e a mamãe } \\
\text { e o papai ali no pátio. Foi uma coisa linda, } \\
\text { nunca deu tristeza. Eu fiquei triste agora } \\
\text { depois que perdi meu marido, perdi a minha } \\
\text { casa, mas eu não tinha..." }\end{array}$ & $\begin{array}{l}\text { "Foi uma coisa linda, nunca deu } \\
\text { tristeza. Eu fiquei triste agora } \\
\text { depois que perdi meu marido, } \\
\text { perdi a minha casa, mas eu } \\
\text { não tinha..." }\end{array}$ & Infância ótima. \\
\hline
\end{tabular}

Foram garantidos a privacidade e o anonimato dos participantes, assim como a confidencialidade dos dados. Os dados brutos são de acesso restrito da pesquisadora e da orientadora, assim como os Termos de Consentimento Livre e Esclarecido, devidamente assinados pelos voluntários. Considerando que o Comitê de Ética da Universidade Federal do Rio Grande - FURG não aprecia propostas na área da Educação, entretanto, foram respeitadas todas as normas de pesquisa com seres humanos previstas pelo Conselho Nacional de Saúde, conforme Resolução n.ํㅜ 196/96.

\section{Resultados}

Foi possível constatar, através das sinopses das histórias de vida das quatro idosas, conforme segue abaixo, algumas considerações para discussão:

- História de vida de Dona Vera Maria: retrata uma infância muito tranquila, junto aos seus pais e irmãos. Como ela mesma disse: “Foi uma coisa linda, nunca deu tristeza...", não recordando de nenhum fato que a tenha deixado 
triste nessa fase da vida. Segundo ela a infância era: "[...] só brincar e estudar e fazer a lida da casa". Dona Vera Maria estudou até os 14 anos e concluiu a $6^{a}$ série do ensino fundamental, lamentou muito o fato de não ter podido estudar, já que sempre gostou de aprender tudo o que despertava sua curiosidade.

Afirmou que o seu marido foi o primeiro e único namorado. As atividades sociais daquela época resumiam-se apenas na "matinê". Na vida adulta, segundo seus relatos, foi muito feliz. Gostava do serviço doméstico, convivia bem com o marido e com os filhos, sem brigas. Falou sobre o bom relacionamento entre as famílias do marido e a sua, lamentou muito as perdas dos entes queridos, conforme falou: "Era uma reunião lá em casa, a família dele com a minha, sempre estavam juntos. Não dava briga, não dava nada, como era bom. E Deus levou tudo, levou tudo guria, tudo, tudo...".

A velhice está sendo para esta idosa uma das fases mais difíceis da vida. Auxiliada por cadeira de rodas para locomover-se, encontra-se limitada fisicamente. Quando a questionei se houve planejamento da sua velhice, Dona Vera Maria respondeu objetivamente que não. Lamenta suas perdas e reafirma sua fé, notável na expressão que segue: "Perdi tudo, tudo, tudo. Se não é eu rezar as minhas oração, conversar com Deus, Jesus, eu não aguentava. Ele me dá força, Jesus nosso senhor, ele me dá força...". A análise desta entrevista e os conhecimentos advindos da experiência de vida de Dona Vera Maria, reporta a importância de relações afetivas saudáveis entre as pessoas e da influência do meio ambiente como espaço para expandir essas interações.

- História de vida de Dona Carolina: é auxiliada por andador ou cadeira de rodas para locomover-se. De comportamento calmo e por vezes apático, passa os dias no asilo sem grandes objetivos. Ao iniciarmos nossa entrevista, questionei-a sobre sua infância, como foi e com quem viveu, enfim, solicitei que narrasse tudo aquilo que se lembrava da época em que fora criança.

Dona Carolina lembrou imediatamente do tempo em que viveu, segundo ela no asilo, cuja instituição se referia a um internato. Recordou um pouco mais atrás e declarou ter morado antes do internato com a mãe e os irmãos. Perguntei pelo pai dela, e ela respondeu que não teve pai. Mesmo assim, afirmou que a infância foi boa, como ela mesma disse: "Acho que foi boa, acho que foi boa." Quando a indaguei sobre as brincadeiras que gostava na infância, tive como resposta imediata: "Ah, gostava de brincar de roda...". Ela estudou, não sabe exatamente, se foi até o $4^{\circ}$ ou $5^{\circ}$ ano, pois precisou sair da escola para trabalhar. Trabalhou em casa de família e cuidando de crianças.

Continuando, questionei sobre bailes, namoros, enfim... Acontecimentos que fazem parte da mocidade. A reação da idosa foi de alegria e risos, quando me confessou que ia muito a bailes. A mãe de Dona Carolina é quem a levava e 
ninguém mais. Ao lembrar-se dos fatos vivenciados na adolescência, dos bailes

e dos vários namorados que teve não se lembra dos sonhos que tinha naquela época de moça. Lembrou apenas que gostaria de sair do internato.

Na vida adulta, Dona Carolina casou-se por volta dos 20 anos, não lembra com exatidão da idade e teve apenas um filho. Quando casada, gostaria de ter tido mais filhos, mas o marido dizia que a vida era muito cara para ter mais de um. Disse que perdeu o marido pelo motivo de bronquite asmática e com maior pesar ainda, falou da perda do filho, assim como relatou: "Meu filho... meu filho não casou era solteiro. Ele não casou que era pra... pra me cuidar". Até sua morte, moravam os dois juntos, ela e o filho, na mesma casa. Depois de sua perda, disse que se sente sozinha no mundo, embora tenha uma afilhada, que é sua tutora e a considera como filha.

Quando a questionei se havia feito um planejamento de sua velhice, Dona Carolina me respondeu: "Quando que eu pensei que eu ia tá aqui. Que eu ia tá aqui no asilo". Declarou não ter ficado na sua casa por desespero da morte do filho, saindo no mesmo dia em que ele morreu. Acha que os idosos são bem tratados no asilo e que seu sentimento de tristeza é pelo fato de não ter mais seu filho.

- História de vida de Dona Eugênia: recorda que as lembranças da sua infância ficaram em torno de dificuldades financeiras. Teve uma infância muito sacrificada junto a sua família. Segundo seu depoimento, sua mãe teve vinte e um filhos e apenas sete sobreviveram. Seu pai faleceu quando tinha dez anos de idade, até sua morte, conviveu junto com seus pais. Afirmou: "Quando eu era criança eu fui criada com muita pobreza, muita pobreza mesmo...".

Lembrou que gostava muito de brincar de roda e foi com treze anos que frequentou pela primeira vez a escola, permanecendo por apenas um mês. Tinha que ajudar a mãe a cuidar dos irmãos e auxiliá-la nas tarefas da casa. Conseguiu ser alfabetizada quando adulta por uma de suas filhas. Dona Eugênia quando recordou sobre a sua infância se deteve muito na frase: "Não sei minha filha, passei muito trabalho". Lembrou apenas das dificuldades, da falta de alimentos, roupas, brinquedos e do trabalho passado pela mãe para cuidar dos filhos.

Casou-se aos dezoito anos e seu marido não foi seu primeiro namorado. Teve alguns outros namorados antes, mas nada sério. Conheceu seu marido num aniversário. Confessou que não casou com ele envolvida por paixão e sim por necessidade, como assim consta em sua fala: "Ah! Porque a necessidade obriga também obriga a gente". Sua mãe a prendia muito e o marido era muito ciumento. Disse que não trabalhou fora de casa quando casada, apenas auxiliava o marido na chácara que tinham, pois ele era agricultor. Tiveram em sua união cinco filhos, e relatou que perdeu dois deles. Também falou que teve uma vida 
de casada feliz, já que nunca passou fome ao lado da família. Embora o marido fosse muito ciumento e nervoso, nunca a agrediu fisicamente. Dona Eugênia é viúva há quinze anos e chegou a completar 60 anos de casada.

Dona Eugênia sofreu muito na vida e admitiu que sua velhice no asilo foi planejada. Desde quando o marido começou a adoecer a idosa declarou que moraria na instituição, o que acabou por fazer. Embora viva relativamente bem com a escolha que fez, internamente sofre com sentimentos de menos valia pelos familiares.

- História de vida de Dona Lúcia Helena: ao lembrar-se da sua infância, assim comentou: "Eu digo: olha eu até que sou muito conformada porque eu não tive infância, não tive mocidade". Esta idosa narrou com certo pesar os acontecimentos da infância, principalmente quando falou do pai que abandonou a família quando ainda era pequena. Não conseguiu permanecer na escola além da $1^{\underline{a}}$ série, pois precisava ajudar a mãe em casa e cuidar das irmãs. Sua frequência no primeiro ano foi muito precária, embora apreciasse estudar. Aprendeu a ler e a escrever com muita dificuldade e aos quatorze anos começou a trabalhar.

Confessou que conheceu aos quatorze anos o seu marido e ele foi seu único namorado. Aos dezesseis anos estava casada, assim como falou: "Me casei com 16. Por isso que eu digo que eu não tive infância". Com vinte e um anos Dona Lúcia Helena já tinha três filhos: duas meninas e um menino. A última menina ela perdeu com três anos. Quando a questionei sobre o tempo que permaneceu casada, ela relatou: "[...] perguntaram esses dias quantos anos eu tive de casada. Eu disse que eu tive quarenta e um ano, agora eu não sei se eu aturei ele ou ele me aturou. Nós se aturemo quarenta e um ano, porque tinhas as esquisitices dele. Mas deu para aguentar...".

A idosa se vê hoje como uma pessoa feliz, assim como afirmou: "Eu acho que eu sou mesmo, me sinto feliz. O que é que eu vou fazer?" Disse que a pensão que recebe do marido é o suficiente para passar bem, sem dificuldades durante o mês, como assim narrou: "O que meu marido me deixou, não sou rica e nem posso botar fora... Mas dá pra mim chegar ao fim do mês". Afirmou que a sua velhice começou a ser planejada no momento em que seu filho se separou, já que tinha uma forte ligação com a nora. Antes disso, só pensava em poder viajar na velhice e aproveitar o que não pode fazer enquanto casada.

Nesse sentido, foi possível observar brevemente a trajetória de vida dessas idosas. Residindo dentro do asilo por "opção", estas idosas escolheram a instituição como alternativa mais viável em suas vidas. Não dão trabalho a nenhuma pessoa da família para cuidá-las, tem suas necessidades como a alimentação, saúde, limpeza dos quartos e outras atendidas, sem esforço pessoal para isso, 
já que são limitadas por causa da saúde. Em contrapartida, sentem-se muito carentes, com sentimentos de desvalia e desamor. Consideram a velhice uma fase muito difícil, pela solidão, pelas doenças, sem mostrar entusiasmo e objetivos para melhorarem suas condições.

\section{Discussão}

As inserções no microssistema da instituição pesquisada foram relevantes quando objetivaram a necessidade de maiores informações sobre as características biopsicossociais dos idosos, buscando interações mais positivas dentro do asilo e em suas relações familiares. Observa-se que há semelhanças no perfil social e afetivo destas idosas que passaram por várias transições ecológicas no decorrer da vida, sendo o asilo a mais recente.

Na infância das quatro idosas o mesossistema que tem a ver com as inter-relações de dois ou mais contextos em que o indivíduo participa ativamente, de modo geral, foram às relações com a família e com a escola, sendo que para algumas das idosas, nem esses ambientes foram permitidos conviver como se pode observar na fala de Dona Eugênia: "Ler e escrever quem me ensinou a ler e a escrever foi minha filha mais nova".

Situação precária também se observou ao analisar o exossistema destas idosas. Concentravam-se nas relações de trabalho das mães em geral e consequentemente, nas dificuldades financeiras que tinham para sobreviverem como assim narrou Dona Carolina sobre sua saída do internato: "Eu me lembro que foi com quatorze anos que a minha mãe foi lá me tirar, pra mim poder trabalhar, pra ajudar ela".

Examinando a influência macrossistêmica sobre o desenvolvimento humano destas idosas na instituição, nota-se a falta de planejamento da velhice na maioria dos casos. $\mathrm{O}$ asilo acaba por se tornar um refúgio mais seguro e cômodo para esses idosos e não uma escolha para condicionar uma qualidade melhor no envelhecimento. Assim, como relata Dona Vera Maria sobre os maus-tratos do neto esquizofrênico quando residia com sua filha: "Mas até hoje me dói o soco que ele me deu...".

Diante de tudo que foi coletado, através das falas das entrevistadas e também do referencial teórico pesquisado, foi possível observar os sentimentos de solidão, abandono, tristeza pelas perdas afetivas, pela falta de convívio familiar, pelas oportunidades que não foram aproveitadas. Idosos que buscam ser mais independentes, que direcionam suas vidas em algo que lhes dê prazer e 
satisfação pessoal, consequentemente aumentam sua autoestima e se sentem mais valorizados. Sem uma rotina de atividades na instituição ficam sem objetivos, deprimidos e limitados em seus desenvolvimentos.

A respeito da interação do idoso no microssistema familiar, Porto (2009, p. 190) assim escreve:

\begin{abstract}
À medida que as pessoas avançam em idade vão se afastando do mundo do trabalho, diminuindo suas interações sociais. A família então se reveste de maior importância, pois é nela que o idoso procura um abrigo seguro para vivenciar seus últimos anos de vida. O carinho e o respeito da família contribuem decisivamente para um final de vida feliz. A vivência plena do envelhecimento é um processo de construção pessoal altamente influenciado pela convivência familiar e comunitária, onde o respeito, a consideração e a comunicação são fatores fundamentais para o alargamento, elevação e otimização das participações individuais e sociais.
\end{abstract}

Para Zimerman (2007), viver em uma instituição implica, muitas vezes, polêmica. As pessoas criticam as famílias por não se responsabilizarem por seu idoso, deixando-os abandonados e carentes. Ao mesmo tempo, alguns idosos vivem em seus núcleos familiares hostilizados e indesejados, vistos como empecilhos para a realização da família.

Pressupõe-se que há uma carência educacional desde a infância até a vida adulta para aceitar e direcionar a vivência nesta fase da vida, visto que é tão sofrida para esta população. A este respeito, Bronfenbrenner sugere: "Nenhuma sociedade pode se sustentar muito tempo a menos que seus membros tenham aprendido as sensibilidades, motivações e habilidades envolvidas na ajuda e no atendimento aos outros seres humanos" (2002, p. 43).

Diante disso, a Educação Ambiental busca a transformação social, a promoção da qualidade de vida das pessoas e a sua emancipação. Loureiro $(2012$, p. 18) aborda essa questão sobre educação e emancipação quando escreve:

\begin{abstract}
Educar é emancipar. A ação emancipatória é o meio pelo qual podemos romper com a barbárie do padrão vigente de sociedade e de civilização. Emancipação e transformação social são elementos que explicitam não se tratar de uma Educação Ambiental genérica, de um conjunto de conceitos que servem indistintamente para qualquer atividade que se autodenomine como Educação Ambiental.
\end{abstract}

Esta investigação apresentou algumas limitações como: a carência de projetos educacionais na instituição que favoreçam momentos que despertem a curiosidade, a criatividade dos idosos respeitando suas limitações. Fazendo com que se sintam mais úteis é possível diminuir suas 
carências afetivas e sociais formando através das atividades de aprendizagens hábitos essenciais para a qualidade de vida.

As principais perspectivas e contribuições apresentadas neste estudo se referem aos breves relatos das histórias de vida de idosos institucionalizados no seu microssistema oportunizando assim, conhecer um pouco dos sentimentos pertencentes a estes idosos e suas fragilidades. A partir das conclusões abstraídas do estudo percebe-se a necessidade de intervenções positivas nos contextos, seja no ambiente institucional ou familiar, inserindo atividades motivadoras e criativas em suas rotinas, contribuindo para tornar seu desenvolvimento mais humano.

\section{6 considerações finais}

Este artigo se propôs a realizar um estudo a respeito do envelhecimento humano, meio ambiente e educação ambiental. Sendo a Educação Ambiental a reformulação dos valores humanos num processo contínuo de permanente aprendizado e de cooperação coletiva, vinculam-se também as questões sobre o envelhecimento humano. Os idosos estão relacionados com a educação ambiental num propósito de socialização permanente e de valorização humana, para que não se tornem vítimas do processo de exclusão social.

Respondendo ao objetivo geral desta pesquisa, torna-se cada vez mais fundamental e imperiosa a produção de conhecimentos sobre o envelhecimento humano. Ter consciência de que os fatores externos como a alimentação, fumo, álcool, radiação solar, poluição e outros e ainda os fatores internos como saber lidar com as emoções, a disposição de viver e aprender, ter objetivos de vida entre outros, condicionam para um envelhecer mais ou menos saudável.

Por ora concluindo, pode-se dizer que os idosos, principalmente os institucionalizados, devem se abrir para espaços educativos que permitam recuperar a visão integral do ser humano, não só visando atender aos cuidados básicos de saúde e higiene, mas também favorecer qualidade nas suas interações. Os idosos devem ser respeitados e incluídos socialmente, não pelo que possuem materialmente, mas pelo caminho que construíram e que ainda percorrem. Sendo seres que continuam se desenvolvendo são capazes perfeitamente de aprender, de ensinar, de escolher, de criticar, de amar, de sonhar e de ser feliz. 
Esta é uma das propostas da Educação Ambiental no contexto do envelhecimento humano, rever o que está sendo ofertado à população idosa que a cada dia cresce em índices estatísticos e que necessita de um olhar mais humanizado e oportunidade de uma sobrevivência mais digna.

Sugeriu-se a instituição pesquisada a realização de tarefas que oportunizem ocupar o tempo dos idosos e mantê-los ativos, com rotinas adaptadas às suas condições físicas e psicológicas; promover novas aprendizagens como: espaços de leituras, para ouvir músicas, danças de salão, cursos de alfabetização, de informática e outros. Investir na qualidade de vida dos idosos institucionalizados requer comprometimento não só da instituição onde estão abrigados e sim, de toda a sociedade.

AGING, THE ENVIRONMENT

AND ENVIRONMENTAL EDUCATION

\section{abstract}

In this article, it is aimed to describe the proximal and conceptual relations of environmental education and their articulations with the elderly people, particularly the institutionalized ones. This theoretical and empirical research was based on what was observed and collected concerning to the socio-affective relations of four elderly people residents of Almshouse of Rio Grande. The main objective of this study is to provoke reflections and questions about the human aging nowadays, considering the influence that the environment has on the quality of aging. This was a qualitative research and had as the base the Ecological Insertion referred in the Urie Bronfenbrenner's bioecological theory of human development. A consistent bibliographical review was done in order to have more knowledge about the theme using as a data collection tools semistructured interviews and field diary. The employed methodology was the life history that allowed to be established a closer relationship with the researched population and then to reach the proposed objectives. It was concluded that the issues related to aging should be problematized by society through educational and environmental actions, permitting a better development for the elderly. The results of this study suggest creating educational spaces within the institution, seeking to recover the full view of the human being and higher 
quality in their social and affective interactions. The theme of this research is considered scientifically relevant, due to the increase in life expectancy and consequently, the increase of social impacts caused by the population growth of elderly people.

keywords

Aging. Elderly. Environmental Education.

\author{
referências
}

BRASIL. Lei no 8842, de 04 de janeiro de 1994. Dispõe sobre a política nacional do idoso, cria o Conselho Nacional do Idoso e dá outras providências. Presidência da República: Casa Civil, subchefia para assuntos jurídicos. Brasília, DF, 5 jan. 1994. Disponível em: <http://mmw.planalto.gov.br/ccivil_03/leis//8842.htm>. Acesso em: 22 jul. 2013.

BRONFENBRENNER, Urie. A Ecologia do Desenvolvimento Humano: experimentos naturais e planejados. Porto Alegre: Artes Médicas, 2002.

Bioecologia do desenvolvimento humano: tornando os seres humanos mais humanos. Porto Alegre: Artmed, 2011.

CAMARANO, Ana A.; KANSO, Solange. Como as famílias brasileiras estão lidando com idosos que demandam cuidados e quais as perspectivas futuras? A visão mostrada pelas PNADs. In: CAMARANO, Ana A. (Org.). Cuidados de Longa Duração para a População ldosa: um novo risco social a ser assumido? Rio de Janeiro: IPEA, 2010. p. 93-122.

$\mathrm{CHIZZOTTI,} \mathrm{Antonio.} \mathrm{Pesquisa} \mathrm{qualitativa} \mathrm{em} \mathrm{ciências} \mathrm{humanas} \mathrm{e} \mathrm{sociais.} \mathrm{2.} \mathrm{ed.} \mathrm{Rio} \mathrm{de}$ Janeiro: Vozes, 2008.

FERREIRA, Lucas Lima et al. Perfil sociodemográfico e funcional de idosos institucionalizados. Estudos Interdisciplinares sobre o Envelhecimento, Porto Alegre, v. 17, n. 2, p. 373-386, dez. 2012.

IBGE (Instituto Brasileiro de Geografia e Estatística). Síntese de Indicadores Sociais: índice de envelhecimento no Brasil. 2012. Disponível em: <http://www.ibge.gov.br>. Acesso em: 22 jul. 2013.

JOVCHELOVITCH, Sandra; BAUER, Martin W. Entrevista Narrativa. In: BAUER, Martin W.; GASKELL, George (Org.). Pesquisa qualitativa com texto, imagem e som: um manual prático. Petrópolis: Vozes, 2002. p. 90-113.

LOUREIRO, Carlos F. B. Trajetória e Fundamentos da Educação Ambiental. 4. ed. São Paulo: Cortez, 2012.

OST, Mariana Afonso et al. Aspectos Psicológicos do Envelhecimento: um estudo com idosos fisicamente ativos. In: Trabalhando com a Terceira Idade: Trajetórias de Intervenção. Pelotas: Editora e Gráfica UFPEL, 2009. p. 187-194.

PORCIUNCULA, Anacirema da S. Idosos institucionalizados no Asilo de Pobres do Rio Grande: Relações socioafetivas e a Educação Ambiental. 2011. 159 f. Dissertação 
(Mestrado em Educação Ambiental) - Faculdade de Educação, Universidade Federal do Rio Grande, Rio Grande, 2011.

Aprendizagem na Terceira Idade. 2008. 44 f. Monografia (Especialização em Psicopedagogia Clínica e Institucional) - Portal Faculdades, Rio Grande, 2008.

PORCIUNCULA, Anacirema da S.; LOURENÇO, Viviane V. Asilo de Pobres: uma intervenção interdisciplinar. 2005. 66 f. Trabalho de Conclusão de Curso de Especialização (Especialização em Educação Brasileira) - Departamento de Educação e Ciências do Comportamento, Universidade Federal do Rio Grande, Rio Grande, 2005.

PORTO, Ivalina. Interação do idoso no microssistema familiar: a percepção dos familiares. Revista de Educação Ambiental da FURG, Rio Grande, v. 14, p. 189-207, 2009.

REIGOTA, Marcos. O que é educação ambiental. 2. ed. São Paulo: Brasiliense, 2009.

ZIMERMAN, Guite. Velhice: aspectos biopsicossociais. Porto Alegre: Artmed Editora Sul, 2007

Recebido: 25/04/2013

Aceite Final: 08/05/2014 